Respiration 2018;96:588-589

DOI: $10.1159 / 000491675$

\section{Bronchoscopic Lung Volume Reduction Treatment Using Endobronchial Valves for Emphysema: Emerging Questions}

\author{
Jorine E. Hartman ${ }^{\mathrm{a}, \mathrm{b}}$ Lowie E.G.W. Vanfleteren ${ }^{\mathrm{c}, \mathrm{d}, \mathrm{f}}$ \\ Eva M. van Rikxoort ${ }^{\mathrm{e}}$ Dirk-Jan Slebos ${ }^{\mathrm{a}, \mathrm{b}}$ \\ on behalf of the SOLVE consortium
}

a Department of Pulmonary Diseases, University of Groningen, University Medical Center Groningen, Groningen, The Netherlands; ${ }^{b}$ Groningen Research Institute for Asthma and COPD, University of Groningen, University Medical Center Groningen, Groningen, The Netherlands; ${ }^{\mathrm{C}}$ Department of Development and Education, $\mathrm{CIRO}+$, Center of Expertise for Chronic Organ Failure, Horn, The Netherlands; ${ }^{d}$ Department of Respiratory Medicine, Maastricht University Medical Center (MUMC+), Maastricht, The Netherlands; ${ }^{e}$ Department of Radiology and Nuclear Medicine, Radboud University Medical

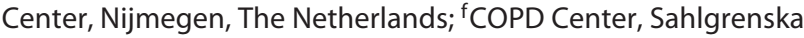
University Hospital and Institute of Medicine, Gothenburg University, Gothenburg, Sweden

In 2017, the GOLD-COPD guidelines included for the first time the bronchoscopic lung volume reduction (BLVR) treatment using one-way endobronchial valves for selected patients with emphysema [1]. This treatment is a therapeutic, minor invasive bronchoscopic strategy for patients with severe lung hyperinflation due to emphysema, who suffer from severe dyspnea despite optimal current available treatment. This treatment has shown to successfully improve pulmonary function, exercise capacity, physical activity, and quality of life [2-5]. All clinical trials performed to date have shown consistent and clinical important outcomes, but have also shown the future challenges of the endobronchial valve treatment.

This point was also highlighted by the GOLD-COPD 2017 report concluding that "additional data are needed to define the optimal patient population to receive the treatment and to define the long-term durability of improvements" [1]. So there is need for additional research to further optimize this promising treatment, with key issues being advanced patient selection, positioning of pulmonary rehabilitation relative to this treatment, target lobe selection, managing adverse events, and long-term follow-up.

For optimal patient selection, i.e., selection of patients with a high likelihood to respond to treatment, it is known that patients need to have emphysema with severe hyperinflation and absence of collateral ventilation from an adjacent lobe to the target lobe for treatment. However, the exact amount of emphysema, hyperinfla- tion, and collateral ventilation still need to be defined to fully optimize and facilitate patient selection. Furthermore, choosing the proper lobar target to collapse is key in the success of endobronchial valve therapy, but might be challenging. Lung volume reduction in emphysema is always balancing between reducing hyperinflation and still maintaining sufficient gas exchange. Combining imaging techniques such as in- and expiratory HRCT scans and lung perfusion scans and further development of quantitative HRCT software analysis with accurate assessment of fissure integrity, emphysema scores, the amount of air trapping, and vascular volume (Fig. 1), all on a lobar level will increase the knowledge on the "best" lobe to treat and result in more insight to predict patients who are at risk of a pneumothorax after treatment, which is the most common risk.

In all GOLD treatment guidelines, pulmonary rehabilitation is an important part of integrated patient management [1]. Most clinical trials investigating the endobronchial valve treatment included only patients who followed regular maintenance physical therapy. However, the combination of endobronchial valve treatment and an actual pulmonary rehabilitation program has never been investigated so far. Combining both treatments could strengthen the effect of the endobronchial valve treatment, especially when the patients' most limiting factor, hyperinflation, has been significantly reduced. Hypothetically, the best timing of the pulmonary rehabilitation program would be after the endobronchial valve treatment instead of before as in current practice. Following, a pulmonary rehabilitation program before and after the endobronchial valve treatment could be even better, but probably not feasible due to high costs.

Furthermore, the endobronchial valve treatment achieved reduction in hyperinflation. The induced improved ventilatory and exercise capacity might cause a lot of metabolic and systemic changes, like cardiac function [6], hypothetically reversing the long-term downward spiral in emphysema patients at multiple organ system levels [7]. This gives us the chance to learn a lot about emphysema pathophysiology in the fields of metabolism, body composition, systemic inflammation, muscle function and structure, cardiac function, and psychological factors.

To date, results have been published on safety and efficacy of the endobronchial valve treatment up to 1 year after treatment [8]. Currently, about 3 out of 4 treated patients retain the valves 1 year later. However, not much is known about the sustainability of the valves in the longer term, how many re-bronchoscopies are necessary to achieve this, and how longer-term data on efficacy and adverse events will look. All this is important for further development of this treatment, but also to make a rational choice to actually be treated.

The Dutch SOLVE consortium (funded by the Dutch Lung Foundation) aims to gain knowledge on all these important additional questions around this innovative BLVR treatment. In this consortium, which was formed in 2017, COPD expertise is com-

\section{KARGER}

E-Mailkarger@karger.com www.karger.com/res
(C) 2018 The Author(s)

Published by S. Karger AG, Basel

Karger
Open access

This article is licensed under the Creative Commons AttributionNonCommercial-NoDerivatives 4.0 International License (CC BYNC-ND) (http://www.karger.com/Services/OpenAccessLicense) Usage and distribution for commercial purposes as well as any distribution of modified material requires written permission.
Jorine E. Hartman, $\mathrm{PhD}$

Department of Pulmonary Diseases AA11

University Medical Center Groningen

PO Box 30001, NL-9700 RB Groningen (The Netherlands)

E-Mail j.hartman@umcg.nl 


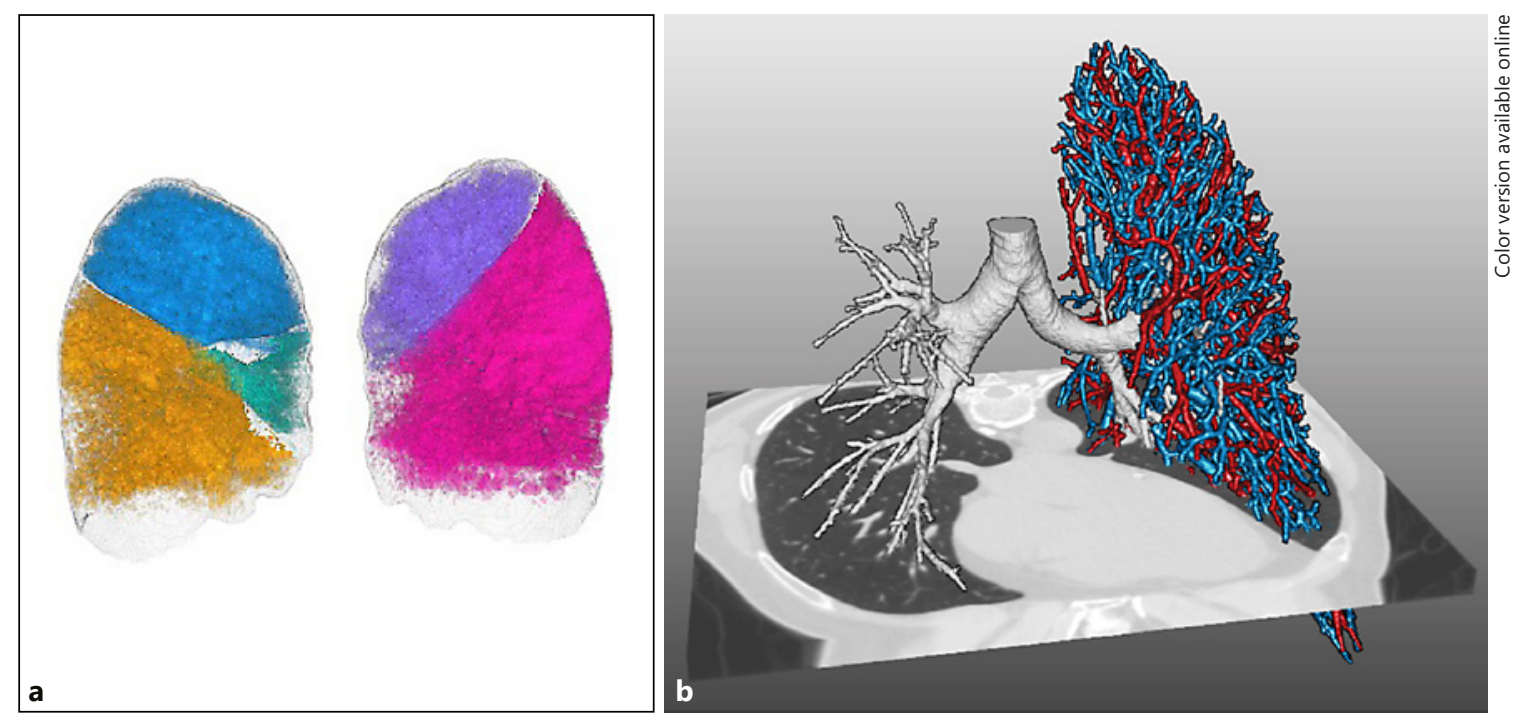

Fig. 1. Example of development of quantitative HRCT software analysis (Thirona, Nijmegen, The Netherlands). a Rendering image of lobar volumes which is used for emphysema scores and air trapping and fissure analysis. b Rendering image of the bronchial tree (right lung) used for airway dimension analysis and pulmonary vasculature, used for vascular volume and lung perfusion.

bined with the world's leading experts on pulmonary rehabilitation, body composition, interventional bronchoscopy, and quantitative imaging. The research that will be performed over the next 5 years will lead to important answers about patient selection, treatment optimization, exact positioning of pulmonary rehabilitation around BLVR, impact on (long-term) efficacy outcomes, and emphysema pathophysiology and hopefully will further develop and optimize this innovative and personalized treatment for this patient group, who have limited treatment options left (see online supplement for the SOLVE study protocol - NCT 03474471; www.karger.com/doi/10.1159/000491675).

\section{Take-Home Message}

The BLVR treatment using one-way endobronchial valves has been shown to successfully improve clinical outcomes but also has some future challenges.

\section{Acknowledgements}

The authors received a grant from the Dutch Lung Foundation for the SOLVE trial (grant number: 5.1.17.171).

\section{Disclosure Statement}

J.E.H. and L.E.G.W.V. have nothing to disclose. E.M.R. is cofounder and shareholder of Thirona. D.-J.S. reports grants from the Dutch Lung Foundation during the conduct of the study; grants, personal fees, non-financial support, and other from PulmonX Inc. CA, USA, outside the submitted work.

\section{Author Contributions}

All authors contributed to the writing of the manuscript.

\section{References}

1 Vogelmeier CF, Criner GJ, Martinez FJ, et al: Global Strategy for the Diagnosis, Management, and Prevention of Chronic Obstructive Lung Disease 2017 Report: GOLD Executive Summary. Arch Bronconeumol 2017;53:128-149.

2 Davey C, Zoumot Z, Jordan S, et al: Bronchoscopic lung volume reduction with endobronchial valves for patients with heterogeneous emphysema and intact interlobar fissures (the BeLieVeR-HIFi study): a randomised controlled trial. Lancet 2015;386:1066-1073.

3 Kemp SV, Slebos DJ, Kirk A, et al: A Multicenter RCT of Zephyr ${ }^{\circledR}$ Endobronchial Valve Treatment in Heterogeneous Emphysema (TRANSFORM). Am J Respir Crit Care Med 2017, DOI: 10.1164/rccm.2017071327OC.

4 Klooster K, ten Hacken NH, Hartman JE, Kerstjens HA, van Rikxoort EM, Slebos DJ: Endobronchial valves for emphysema without interlobar collateral ventilation. N Engl J Med 2015;373:2325-2335.

5 Valipour A, Slebos DJ, Herth F, et al: Endobronchial valve therapy in patients with homogeneous emphysema. Results from the IMPACT study. Am J Respir Crit Care Med 2016;194:1073-1082.

6 Hohlfeld JM, Vogel-Claussen J, Biller H, et al: Effect of lung deflation with indacaterol plus glycopyrronium on ventricular filling in patients with hyperinflation and COPD (CLAIM): a double-blind, randomised, crossover, placebo-controlled, single-centre trial. Lancet Respir Med 2018;6:368-378.

7 Vanfleteren LE, Spruit MA, Groenen M, et al: Clusters of comorbidities based on validated objective measurements and systemic inflammation in patients with chronic obstructive pulmonary disease. Am J Respir Crit Care Med 2013;187:728-735.

8 Klooster K, Hartman JE, Ten Hacken NH, Slebos DJ: One-year follow-up after endobronchial valve treatment in patients with emphysema without collateral ventilation treated in the STELVIO trial. Respiration 2017;93: $112-121$. 